\title{
Pediatrik ayak kırıklarının değerlendirilmesi ve tedavisi
}

\author{
Evaluation and treatment of pediatric foot fractures
}

\author{
Mehmet Ali Talmaç, Mehmet Akif Görgel
}

SBÜ Şişli Hamidiye Etfal Eğitim ve Araştırma Hastanesi, Ortopedi ve Travmatoloji Kliniği, İstanbul

\begin{abstract}
Ayak kırıkları, tüm pediatrik kırıkların \%5-14'ünü ve tüm fizis yaralanmalarının yaklaşık \%7'sini oluşturur. Çocuklarda ayak kırıklarına yetişkinlerden daha az rastlanması kıkırdağın kemiğe göre daha elastik bir yapıya sahip olması ile açıklanabilir. Pediatrik ayak kırıklarının çoğu izole yaralanma olmasına rağmen, bazıları politravma ile birliktedir ve tüm iskelet sisteminin seri muayenesi gereklidir. Bu yaralanmaları tedavi ederken çocuk ayağının anatomisinin tam olarak anlaşılması gerekmektedir. Ayak travması olan bir çocuğun erken ve doğru tanısında fizik muayene ve radyolojik değerlendirme süreçleri erişkinlere göre daha zor olduğu için, şüphe çok önemlidir. Kompartman sendromu şüphesi varsa, kompartman basıncı ölçümleri çok değerlidir. Kırık paternini tam olarak belirlemek ve tedaviyi planlamak için düz radyografilere ek olarak bilgisayarlı tomografi görüntülemesi gerekebilir. Pediatrik ayak kırıklarında genellikle konservatif tedavi ile iyi sonuçlar alınmakla birlikte, bu kırıkların bir kısmı anatomik redüksiyon ve internal tespite rağmen kötü sonuçlara sahip olabilmektedir. Pediatrik ayak kırıklarının tedavisi genellikle iyi sonuçlanır; fakat, özellikle Lisfranc kırıkları, talus boyun ve gövde kırıklarının olası kötü sonuçlarından mümkün olduğunca kaçınılmalıdır.
\end{abstract}

Anahtar sözcülkler: ayak; kalkaneus; pediatrik; talus
Foot fractures account for $5-14 \%$ of all pediatric fractures and approximately $7 \%$ of all physis injuries. The fact that foot fractures in children is less common than adults can be explained by the fact that cartilage has a more elastic structure than bone. Although most of the pediatric foot fractures are isolated injuries, some are associated with the polytrauma and serial examination of the entire skeletal system is required. A thorough understanding of the anatomy of the child foot is essential while treating these injuries. Since physical examination and radiological evaluation processes are more difficult in early and accurate diagnosis of a child with foot trauma, suspicious and cautious approach is very important. If compartment syndrome is suspected, compartment pressure measurements are very valuable. Computerized tomography imaging may be required in addition to plain radiographs to determine the fracture pattern and to plan the treatment. Although pediatric foot fractures usually have good results with conservative treatment, some of these fractures may have poor results despite anatomic reduction and internal fixation. The treatment of pediatric foot fractures usually results in good outcomes, but the possible poor outcomes of the fractures of the Lisfranc, talus neck, and talus body fractures should be avoided as much as possible.

Key words: calcaneus; foot; pediatric; talus
A yak kırıkları, tüm pediatrik kırıkların \%514 'ünü ve tüm fizis yaralanmalarının yaklaşık \%7'sini oluşturur. ${ }^{[1-6]}$ Küçük çocuklarda kıkırdak komponentinin daha fazla olması nedeniyle kırılmaya karşı göreceli direnç vardır ve bu kırıklar çok nadir görülür. Ancak, insidansı yaşla birlikte artar. Çocuklarda ayak kırıklarına yetişkinlerden daha az rastlanması kıkırdağın kemiğe göre daha elastik bir yapıya sahip olması ile açıklanabilir. ${ }^{[2-5]}$ Falanks kırıkları
11-15 yaşlarda, diğer ayak kırıkları ise 0-6 yaşlarda daha sık görülür. ${ }^{[4]}$ Çoğu travmatik yaralanmada olduğu gibi, pediatrik ayak kırıklarına da erkek çocuklarda daha sık rastlanır.

Pediatrik ayak kırıklarında genellikle konservatif tedavi ile iyi sonuçlar alınmakla birlikte, bu kırıkların bir kısmı anatomik redüksiyon ve internal tespite rağmen kötü sonuçlara sahip olabilmektedir. ${ }^{[1-3]}$ Pediatrik ayak kırıklarının yönetiminde en önemli zorluklar; cerrahi

- Illetişim adresi: Uzm. Dr. Mehmet Ali Talmaç, Şişli Hamidiye Etfal Eğitim ve Araştırma Hastanesi, 19 Mayıs Mah., Etfal Sok., Şişli, İstanbul Tel: 0555 - 5529329 e-posta: drtalmac2@gmail.com

- Geliş tarihi: 2 Şubat $2019 \quad$ Kabul tarihi: 2 Şubat 2019 
tedavi gerektiren kırıkların belirlenmesi, kompartman sendromunun önlenmesi, travma sonrası ayak deformiteleri ve avasküler nekroz gibi komplikasyonların tedavilerinin tanımlanmasıdır. ${ }^{[4]}$ Ayak kırığı olan çocukların optimal değerlendirilmesi ve tedavisi için ayak anatomisinin, özellikle de fizis yaralanmasının yeri ve doğasının kapsamlı bir şekilde anlaşılması gerekmektedir.

\section{ANATOMi}

Ayak üç ana alt bölümden oluşmaktadır: ayak önü, ayak ortası ve ayak arkası. Ayak önü, metatarsal kemikler ve falankslardan oluşur. Metatarsal kemiklere ait fizisler distalde, falankslara ait fizisler proksimaldedir. Ayağın bu ön kısmı, orta kısımdan tarsometatarsal (Lisfranc) eklem ile ayrılır. Tarsometatarsal eklemler, kemik ve ligamentöz yapıların bir sonucu olarak güçlü bir stabiliteye sahiptir. ${ }^{[5]}$ ikinci metatarsın bazisi mediyal ve lateral küneiformlar arasında kilitlenerek metatarsal kemiklerin mediolateral translasyonunu sınırlar. ${ }^{[6]}$ Ayrıca orta üç metatarsal bazisin, yan yana geldiğinde, sagittal düzlemde stabilite sağlayan bir "Roma kemeri" konfigürasyonu oluşturduğu bilinmektedir. ${ }^{[5]}$

Ayak ortası tarsal kemikleri (naviküler, küboid ve küneiformlar) içerir. Talus, navikula, kalkaneus ve küboid kemiklerin arasındaki eklemleşme (Chopart eklemi), transvers tarsal eklem olarak adlandırılan fonksiyonel bir birim oluşturur. Bu arka, orta ve ön kısımlar, vücudu desteklemek, kurvetleri dağıtmak ve ambulasyon için rijid bir temel sağlamak üzere kolektif olarak işlev görür. ${ }^{[4]}$ Lisfranc eklemi, buradaki yaralanmalar çoğu kez kaçırıldığı için özel bir dikkat gerektirir. ${ }^{[7]}$ Transvers bağlar, lateral dört metatarsal kemiğin bazislerini birbirine bağlar; bununla birlikte, 1 . ve 2 . metatarsal kemiklerin bazisleri arasında böyle bir transvers bağ yoktur. ${ }^{[3]}$ Lisfranc bağı esas olarak 2. metatarsın plantar bazisini mediyal küneiformun plantar yüzeyine bağlar. Ayak arkası, subtalar eklemde eklemleşen talus ve kalkaneustan oluşur. ${ }^{[5]}$

\section{TANI}

Pediatrik ayak kırıklarının çoğu izole yaralanma olmasına rağmen, bazıları politravma ile birliktedir ve tüm iskelet sisteminin seri muayenesi gereklidir. Yapılan bir çalışmada, ayak veya ayak bileği yaralanması olan 125 hastanın 21'inde (\%17) başka bir iskelet yaralanması da olduğu bildirilmiştir. ${ }^{[8]}$ Masif yumuşak doku hasarı olan hastaların değerlendirilmesinde bazı zorluklar vardır. Her ne kadar non-koopere bir çocukta zor olsa da, dikkatli bir fizik muayene şarttır. Distal nabızların palpasyonu ve kapiler dolumun değerlendirilmesi önemlidir. Distal nabızların palpe edilememesi durumunda, genellikle Doppler ultrasonografi ile değerlendirme gereklidir. Yaralanma bölgesinin duyu muayenesi unutulmamalıdır.

Yetişkinlerde olduğu gibi, yüksek enerjili yaralanmalardan sonra kompartman sendromu ortaya çıkabilir. ${ }^{[9]}$ Etkilenen ayak genellikle çok ağrılı ve ödemli olabilmektedir. Kompartman sendromu şüphesi olan bir çocuğun değerlendirilmesinde, özellikle kırık ile ilişkili ödem ve pasif hareketle orantısız ağrı varsa, kompartman basıncı ölçümleri çok değerlidir. Kompartman basıncı 30 mm Hg'yı aşarsa fasyotomi yapılmalıdır. ${ }^{[9,10]}$

Ayak travması olan hastaları değerlendirmek için en sık anterior-posterior (AP), lateral ve oblik radyografiler kullanılır. Lateral görüntüde belirgin osseöz örtüşme olması nedeniyle, AP ve lateral görünümleri desteklemek için oblik radyografiler de gereklidir. Karşılaştırmalı radyografiler kullanılabilmekle birlikte, normal radyografik görünüme aşina olan bir ortopedist için nadiren gerekli olur. ${ }^{[11]}$ Bazen ayak sesamoid kemikleri ve fizisler düz radyografilerde kırık ile karıştırılabilmektedir. Yanlış pozitiflikten kaçınabilmek için, düz radyografilerin fizik muayene bulguları ile korele bir şekilde değerlendirilmesi gerekir. Kırık paternini tam olarak belirlemek ve tedaviyi planlamak için bilgisayarlı tomografi (BT) görüntülemesi gerekebilir. Manyetik rezonans (MR) görüntülemesi rutin olarak kullanılmamakla birlikte, şüpheli olgularda gerekebilir.

\section{TALUS KIRIKLARI}

Çocuklarda talus önemli ölçüde kıkırdaktan oluştuğu için yüksek elastik dirence sahiptir. Tüm pediatrik ayak kırıklarının sadece \%2'si talus kırıklarıdır. ${ }^{[12]}$ Yapılan çalışmalarda, en yaygın pediatrik talus kırığının, boyun ve takiben gövde kırığı olduğu belirtilmektedir. ${ }^{[13]}$ Talar baş kırıkları genellikle, midtarsal eklem (Chopart) dislokasyonuna sekonder olarak ortaya çıkar. ${ }^{[6]}$ Buna karşı।ık, periferik talus kırıkları (lateral ve posterior çıkıntı) çok nadirdir ve bu yaş grubunda teşhis edilmesi güçtür. Kesin tanı için BT gerekir. ${ }^{[14]}$

Yetişkinlerde olduğu gibi, talus boyun ve gövde kırıkları ayak bileğinin kuvvetli dorsifleksiyonundan kaynaklanır. Çocuklarla ilgili olarak bildirilen serilerde, yaklaşık \%80 yüksekten düşme veya motorlu araç kazası sonrası başvurulduğu belirlenmiştir. ${ }^{[15,16]}$ Talus boyun ve gövde kırıkları, iki yaşından küçük çocuklarda bile bildirilmiştir. ${ }^{[15,16]}$ On iki yaş ve üzerinde, yüksek enerjili travma sayısı ve dolayısıyla kırığın ciddiyeti artar. $^{[6]}$

Talus kırıklarının semptom ve bulguları arasında; ayak bileği veya arka kısmının ağrısı, lokal hassasiyet 


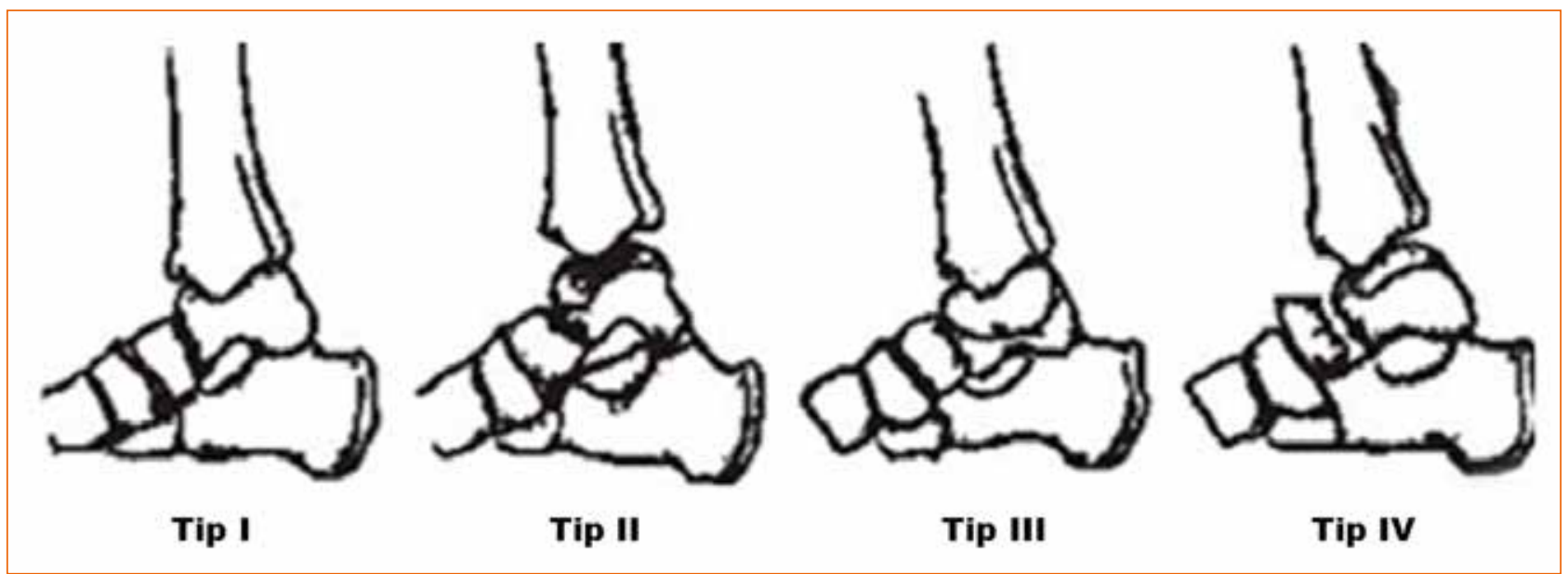

Şekil 1. Talus kırıklarının Hawkins sınıflaması. (M. A. Görgel'in arşivinden)

ve ayak bileği dorsifleksiyonu ile ağrı vardır. Bazen lokal şişlik olabilir. Düz radyografiler kırık hattını ve deplasman miktarını tanımlamada genellikle yeterlidir. ${ }^{[16]}$ Kırık konfigürasyonu ve deplasmanının değerlendirilmesinde BT yardımcı olabilir.

Pediatrik talus boyun kırıklarının sınıflandırılmasında, yetişkinlerde olduğu gibi, Hawkins sınıflama sistemi kullanılmaktadır (Şekil 1). ${ }^{[14]}$ Tip I kırıklar deplase olmayan kırıklardır. Tip II kırıklar subtalar eklemin subluksasyonu veya çıkığı ile birlikte olan talus boyun kırıklarıdır. Tip III kırıklar subtalar ve tibiotalar eklemin subluksasyon veya dislokasyonu ile birlikte olan talus boyun kırıklarıdır. Son derece nadir görülen Tip IV yaralanmalar ise, yer değiş̧tirmiş talus boyun kırı̆̆ı, talus başının talonaviküler eklemden subluksasyonu ve subtalar ve/veya tibiotalar eklemlerin subluksasyonu veya dislokasyonu ile karakterizedir. ${ }^{[5]}$

Konservatif tedavi sadece minimal deplase veya deplase olmamış kırıklarda önerilmekle birlikte, tüm deplase talus kırıkları için tercih edilen tedavi, anatomik redüksiyon ve stabil internal tespittir (Şekil 2). ${ }^{[6]}$ Tespit, mekanik verimliliği dengeleyen ve kıkırdak hasarını en aza indiren vidalarla yapılmalıdır; küçük çocuklarda Kirschner teli (K-teli) ile yeterli stabilite sağlanır. ${ }^{[17]}$ Osteokondral parçalar, fibrin yapıştırıcı veya emilebilir pinlerle sabitlenir. ${ }^{[6]}$ Devam eden instabilite, kapsüloligamentöz yaralanmaya veya kemik parçalanmasına bağıdır; ciddi yumuşak doku yaralanması varsa, eksternal fiksatörden yararlanılabilir. ${ }^{[17]}$

Talusun kruris ve ayak arkasındaki merkezi konumu ve üç kilit eklemdeki pozisyonu nedeniyle; dizilim bozuklukları, eklem uyumsuzluğu, eklem içi parçalar

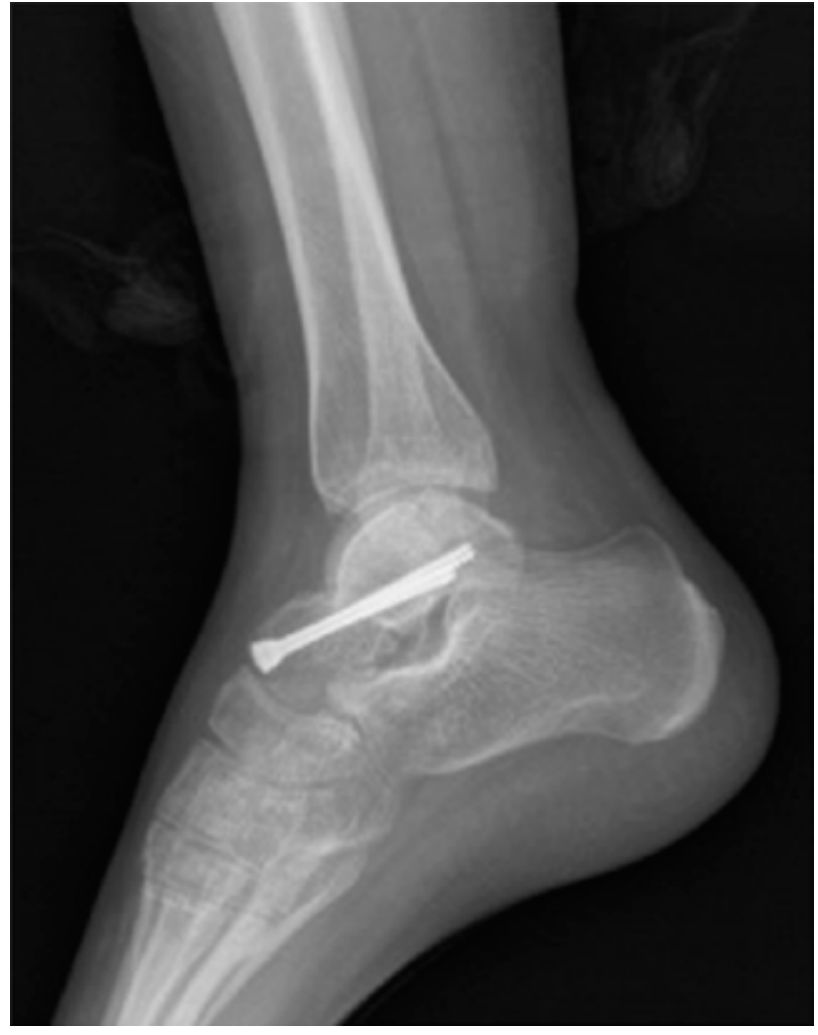

Şekil 2. Sağ talus boyun kırığı nedeniyle iki adet kanüllü kompresyon vidası ile kapalı redüksiyon ve internal tespit yapılan 14 yaşında erkek hastanın, operasyondan bir yıl sonraki lateral grafisi.

veya yetersiz osteosentez, ayak bileğinde önemli kısıtIılıklarla sonuçlanabilir. ${ }^{[6]}$ En önemli problemler; talus boynunun varus deformitesi, ayak mediyal kolonunun kısalması, eklemde dizilim bozukluğu ve aksiyel deplasmandır. ${ }^{[1]}$ 


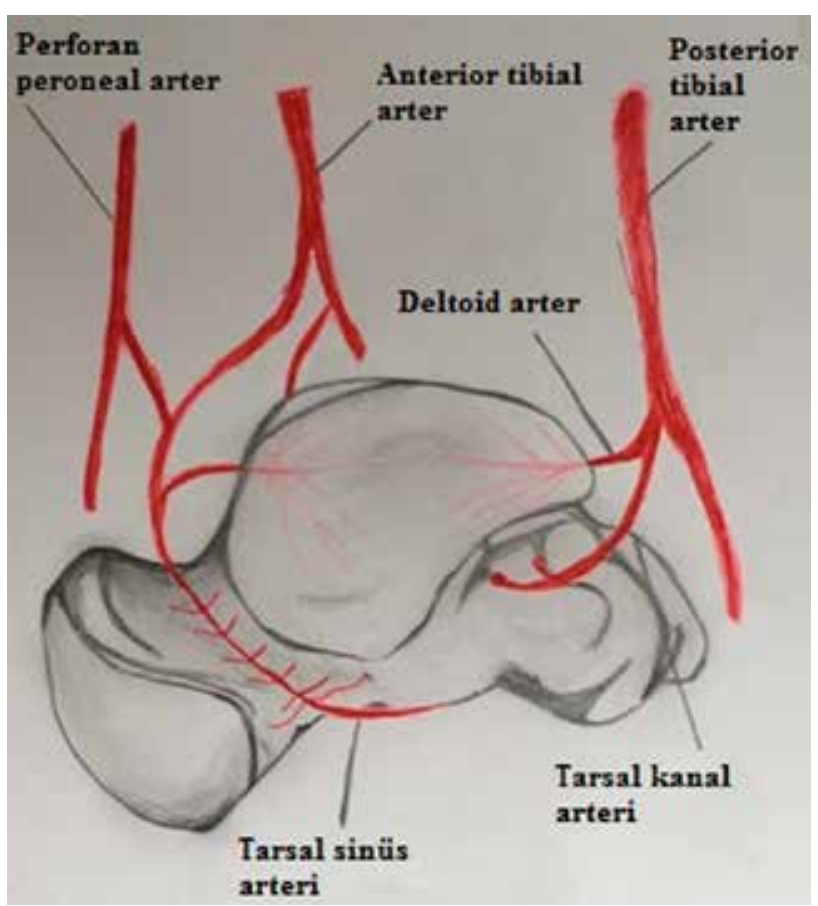

Şekil 3. Talusun kanlanması. (M. A. Talmaç'ın arşivinden)

Talusun primer kanlanmasi; sinus tarsi, tarsal kanal, posterior tüberkül, superior boyun ve mediyal gövdeden kemiğe penetre olan arteriyel bir ağdan sağlanır. Posterior tibial arter, dorsalis pedis ve perforan popliteal arterden de katılım olmaktadır (Şekil 3).

Talus osteonekrozu, talus boyun ve gövde kırıklarından sonra, talus boynunu çevreleyen vasküler halkanın bozulması nedeniyle yaygındır. Talus yüzeyi çoğunlukla eklem kıkırdağından oluştuğu için talar kan akımı azdır. ${ }^{[1]}$ Talus boyun kırığı sonrası osteonekroz riski yaklaşık \%50 olup bu oran Tip III ve IV kırıklarda daha yüksektir. ${ }^{[1,2]}$ Düz radyografilerde, talus kubbesinin subkondral kemiğinde, genellikle yaralanmadan 6-8 hafta sonra ortaya çıkan lusensi (Hawkins bulgusu), talus gövdesinin yeterince vaskülarize olduğunu ve osteonekroz riskinin düşük olduğunu gösterir. Teknesyum kemik taraması ve daha sık olarak MR görüntüleme, borderline olgularda osteonekroz varlığını değerlendirmek için yararlı olabilir. ${ }^{[5]}$

Çocuklarda uzun dönem takip sonuçları, talus kırığı sonrası ağrının yaygın olduğunu düşündürmektedir. ${ }^{[15]}$ Ağrının, başlangıçtaki yüksek enerjili yaralanma ile ilişkili kondral hasar veya rezidüel eklem içi uyumsuzluğa bağlı olduğu düşünülmektedir. ${ }^{[5]}$ Deplase talus kırığı olan hastaların radyografik takiplerinde, tibiotalar eklemde artroz geliştiği gösterilmiş olmakla birlikte, subtalar eklemde bu gösterilememiştir. ${ }^{[15]}$

\section{KALKANEUS KIRIKLARI}

Kalkaneus kırıkları, pediatrik ayak yaralanmalarının yaklaşık \%2'sini, tüm çocukluk çağı kırıklarının ise \%0,02'sinden daha azını oluşturur. ${ }^{[6]}$ Yetişkinlerle karşılaştırıldığında, pediatrik kalkaneus kırıkları daha yüksek bir oranda eklem dışı kırıklardır. ${ }^{[18]}$ Kalkaneus kırıklarının mekanizması çoğunlukla aksiyel yüklenmedir. Hastaların yarısından çoğu yüksekten düşme veya motorlu araç kazası sonrası başvurmaktadır.[18] Bu kırıklar genellikle yüksek enerjili bir travma sonrası ortaya çıktığı için, bunların yaklaşık beşte biri politravma ile birliktedir.[${ }^{5]}$ Yapılan bir çalışmada, kalkaneus kırığı olan çocukların \%5'inde vertebra kırığı da olduğu belirtilmiştir. ${ }^{[19]}$

Düz radyografi, öncelikle $A P$, lateral ve aksiyel görünümleri içermelidir. Ayrıca, kırık konfigürasyonunun ilk değerlendirmesinde kalkaneus oblik grafiler yardımcıdır. Lateral grafi, Böhler açısının ölçülmesi açısından önemlidir. Böhler açısı, normalde yetişkinlerde $25-40^{\circ}$ olup çocuklarda daha azdır. Kalkaneus kırığı olan 227 pediatrik hasta ile yapılan bir çalışmada, Böhler açısı ortalamaları 0-5, 5-10 ve $10-15$ yaş gruplarında sırasıyla $15^{\circ}, 55^{\circ}$ ve $37^{\circ}$ olarak bildirilmiştir. ${ }^{[20]}$ Kalkaneusun büyük kısmı çocuklarda henüz kemikleşmediği için, Gisanne açısı genellikle ölçülemez. Adolesanlarda Gissane açısı 125-140 'dir (Şekil 4). ${ }^{[5]}$ Tanıyı doğrulamak ve eklem içi tutulumu dışlamak için BT en iyi görüntüleme yöntemidir. ${ }^{[6]}$

Pediatrik kalkaneus kırıklarının sınıflandırılmasında kullanılan en yaygın sistem Essex-Lopresti'dir (Şekil 5). ${ }^{[3]}$ Bu sisteme göre, kırıklar dil tipi veya depresyon kırıkları olarak sınıflandırılır, ancak en önemli farklııı eklem içi ve eklem dışı kırıklar arasındadır. Eklem dışı kırıklar 3-4 hafta kısa bacak alçı ile tedavi edilebilir. Eklem dışı kırıklar, uzun dönemde nadiren sekel bırakmakla birlikte, topuk yükseklik kaybı ve topuk genişlemesine yol açabilir. Bazı yazarlar eklem içi deplase pediatrik kalkaneus kırıkları için cerrahi tedavi önermekle birlikte, konservatif tedavi ile de iyi sonuçların elde edildiği bildirilmiştir. ${ }^{[21,22]}$ Bu kırıkların küçük çocuklarda tedavisi tartışmalı olmakla birlikte adolesanlarda optimal tedavi olarak "açık redüksiyon internal tespit" (ARIF) tercih edilir (Şekil 6). ${ }^{[6]}$ On beş yaş üstündeki adolesanlar için yetişkin kriterleri uygulanır: eklemde $1 \mathrm{~mm}$ 'den fazla çökme ve karşı tarafla karşılaştırıldığında \%20'den fazla genişleme veya yükseklik kaybı. ${ }^{[23]}$ iki parçalı kırıklarda, K-teli veya vidalar ile kapalı redüksiyon ve perkütan tespit seçenekler arasındadır. Kalkaneus lateral duvarı üzerine uygulanan düşük profilli kilitli plakların kullanımı, son çalışmalarda iyi sonuçlar göstermiştir. ${ }^{[24]}$ 

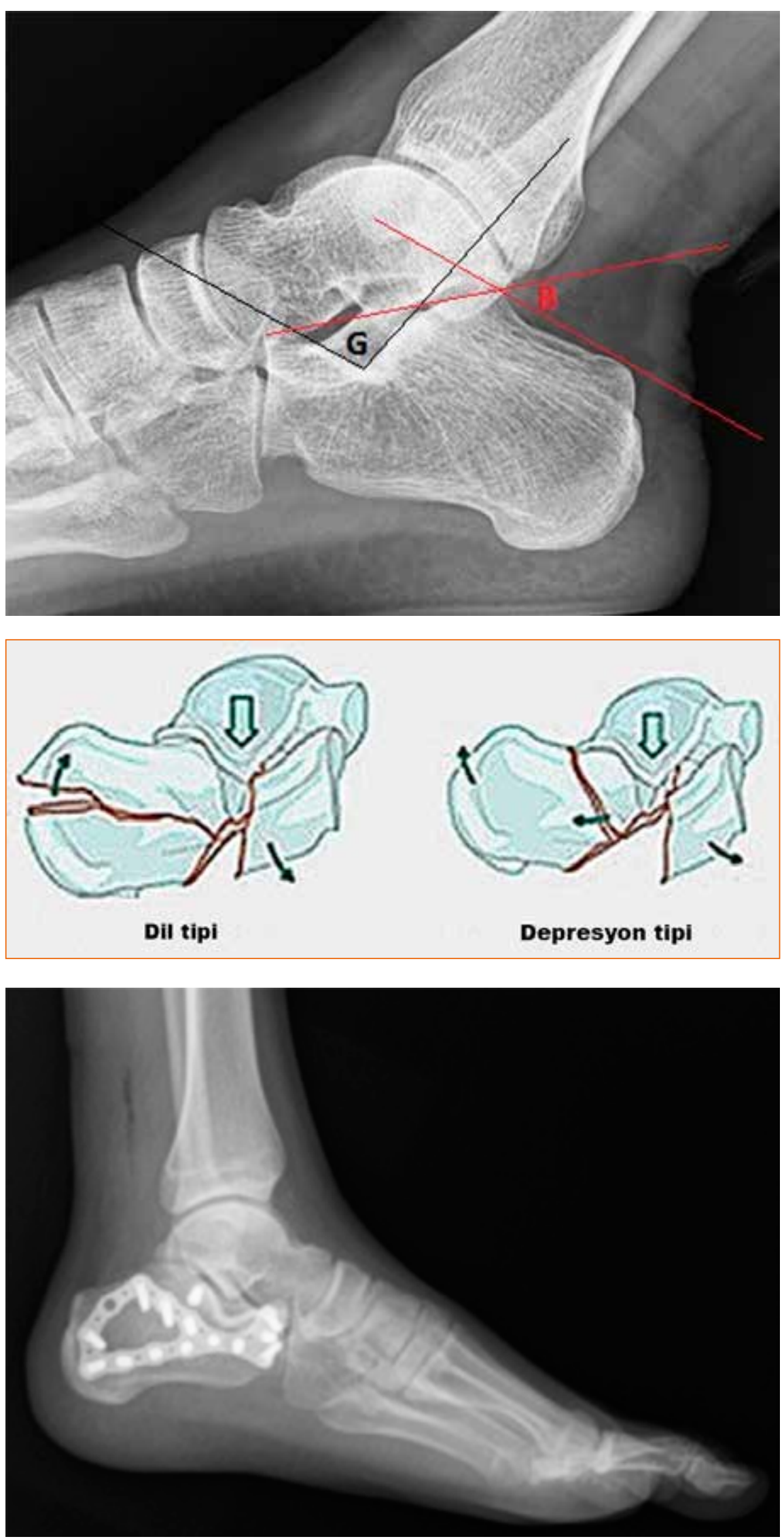

Şekil 4. Ayak lateral grafide Böhler (B) ve Gissane (G) açılarının ölçümü.

Şekil 5. Kalkaneus kırıklarının EssexLopresti sınıflaması. (M. A. Talmaç'ın arşivinden)

Şekil 6. Sol kalkaneus kırığı nedeniyle kilitli anatomik kalkaneus plağı kullanılarak ARIF yapılan 12 yaşında erkek hastanın, operasyondan altı yıl sonraki lateral grafisi. 


\section{DIĞER TARSAL KEMIK KIRIKLARI}

Naviküler, küboid ve küneiform kemik kırıkları, pediatrik ayak yaralanmalarının \%2-7'sini oluşturur. ${ }^{[15]}$ Tarsal kırıkların çoğu avulsiyon veya stres kırıklarıdır. İki ila üç hafta kısa bacak yürüme alçısı ile tedavi edilir. Deplase tarsal kırıklar, genellikle yüksek enerjili travmalar sonrasında oluşur. Bu kemiklerin yüzeylerinin büyük kısmı eklem içi olduğu için, deplase kırıkların tedavisinde kapalı veya açık redüksiyon ve internal tespit gerekebilir. ${ }^{[5]}$ Bu kırıklarda yumuşak doku değerlendirmesi önemlidir ve kompartman sendromu olabileceği de akılda tutulmalıdır.

\section{LISFRANC YARALANMALARI}

Tarsometatarsal eklem yaralanmaları çocuklarda nadir olarak görülür. Yaralanma mekanizması, genellikle aksiyel yüklenme ile birlikte olan ayağın kuvvetli plantar fleksiyonu veya direkt ezilmedir. Hastaların yaklaşık \%60'ı yüksekten düşme sonrası başvurmaktadır. ${ }^{[25]}$

Lisfranc yaralanması olan çocuklarda, önemli yumuşak doku yaralanması da olabileceği için hemen taburcu edilmemeli ve hastane içerisinde takip edilmelidir. Pasif parmak hareketleri ile orantısız ağrı oluşması, kompartman sendromu açısından cerrahı şüphelendirmelidir. Şüphe varsa kompartman basınçları ölçülmelidir. Özellikle mental durum değişikliği olan hastalarda kompartman sendromunun ağrı ile değerlendirilmesi zor olduğu için, kompartman basınçlarının ölçümü çok önemlidir. Kompartman basıncı 30 mm Hg'dan yüksek ise tüm ayak kompartmanları için fasyotomi açılmalıdır. ${ }^{[9,10]}$

Tarsometatarsal eklem plantar bağları daha güçlü olduğu için yaralanma esnasında ilk olarak dorsal bağlar yırtılır; takiben, travmanın yönü ve şiddetine bağlı olarak, sırasıyla plantar bağların yırtığı ve metatarsal kemik bazislerinin plantar yönde yer değiştirmesi gerçekleşebilir. ${ }^{[5]}$ Lisfranc yaralanmaları, tüm tarsometatarsal kompleksi veya bunun herhangi bir kısmını içerebilir. Birinci ve 2. metatarsal kemiklerin bazisleri arasında intermetatarsal bağ olmadığı için, sıklıkla diastazis oluşur. ${ }^{[6]}$ Alternatif olarak, tüm metatarslar aynı yönde yer değiştirir (homolateral yaralanma) veya 1. metatars mediyale diğer dört metatars laterale yer değiştirir (diverjan yaralanma). ${ }^{[25]}$

ilk radyografik değerlendirme; $A P$, oblik ve lateral radyografilerden oluşmalıdır. Yaralanmaların daha belirgin görüntülenebilmesi için, AP ve lateral grafiler ayak üzerine basacak şekilde ağırık verilerek çekilmelidir. ${ }^{[25]}$ Birinci metatars bazis kırıkları yaygındır; ancak 2. metatars bazisinin izole kırığı, Lisfranc kompleksinin yaralandığının bir göstergesi olan bir avulsiyon kırı̆̆ıdır. ${ }^{[5]}$ ikinci metatars mediyal kenarı ile orta küneiformun mediyali, 4. metatars mediyali ile küboidin mediyali aynı hizada iseler, Lisfranc yaralanması şüphesinden uzaklaşılır. ${ }^{[5]}$

Tarsometatarsal eklemde başlangıçta deplase olan bir kırık, spontan redüksiyon ile deplase olmayan bir kırık şeklindeki yaralanma olarak karşımıza çıkabilir. Bu yaralanmalar, altı hafta yük vermeden ve takiben iki hafta yük vererek kısa bacak alçı ile tedavi edilir. Lisfranc kırıklı çıkığı olan hastalar için acil cerrahi tedavi gereklidir. Öncelikle, anestezi altında kapalı redüksiyon denenmelidir. Kapalı redüksiyonun başarılı olması halinde; bunu takiben küçük çocuklarda K-teli, adolesanlarda ise kemik stoğu yeterli olacağı için, kanüllü kompresyon vidaları ile internal tespit yapılmalıdır. Tam anatomik kapalı redüksiyon sağlanamamışsa ARIF endikedir. Lisfranc yaralanmaları ile ilişkili uzun dönem sonuçlar çelişkili olup, kısa dönemde Lisfranc eklemi üzerinde ağrı ortaya çıktığı bildirilmektedir. ${ }^{[26]}$ Perkütan K-teli ile kapalı redüksiyon ve tespit yapılan olgularda, ağrılı deformiteler, yetersiz dizilim veya anatomik olmayan redüksiyona bağlı olarak, nihai sonuçların olumsuz olarak etkilendiği gösterilmiştir. ${ }^{[6]}$

\section{METATARSAL KIRIKLAR}

Çocuk ve adolesanlarda metatarsal fizis kırıkları, tüm fizis yaralanmalarının \%2'sinden azını oluşturmaktadır. Metatarsal kırık mekanizması direkt veya indirekt olabilir. Direkt yaralanmalar, genellikle ayak üzerine ağır bir cisim düşmesi veya bir ezilme sonucudur. Indirekt yaralanmalar, genellikle aksiyel yükleme, inversiyon, rotasyon veya bunların bir kombinasyonundan kaynaklanır. ${ }^{6]}$ Proksimal metatars kırı̆̆ı ile karşılaşıldığı zaman, Lisfranc yaralanmasının eşlik edebilme ihtimali olduğu için, tarsometatarsal eklemin değerlendirilmesi önemlidir. Radyografiler; AP, lateral ve oblik görünümlerden oluşmalıdır (Şekil 7).

Metatars kırı̆ıı proksimalde değilse, kısa bacak yürüme ateli ile tedavi edilebilir. ${ }^{[4]}$ Tedavi süresi genellikle üç haftadır (kırık bölgesinde hassasiyet azalıncaya kadar). ${ }^{[3]}$ Metatars başlarının belirgin sagittal dizilim bozukluğu olduğu nadir durumlarda, ileride transfer lezyonlarından kaçınmak için, kapalı redüksiyon ve internal tespit düşünülmelidir (Şekil 8). ${ }^{[1]}$

Metatarsal kırığın bir sonucu olarak büyüme bozukluğu ortaya çıkabilir. ${ }^{[1]}$ Birinci metatars bazisinin fizis kırıkları, nadir de olsa, potansiyel olarak büyüme bozukluğuna ve 1. parmak kısalığına neden olabilir. ${ }^{[5]}$ Metatarsal kırıklardan sonra aşırı büyüme de olabilir. ${ }^{[1]}$ 


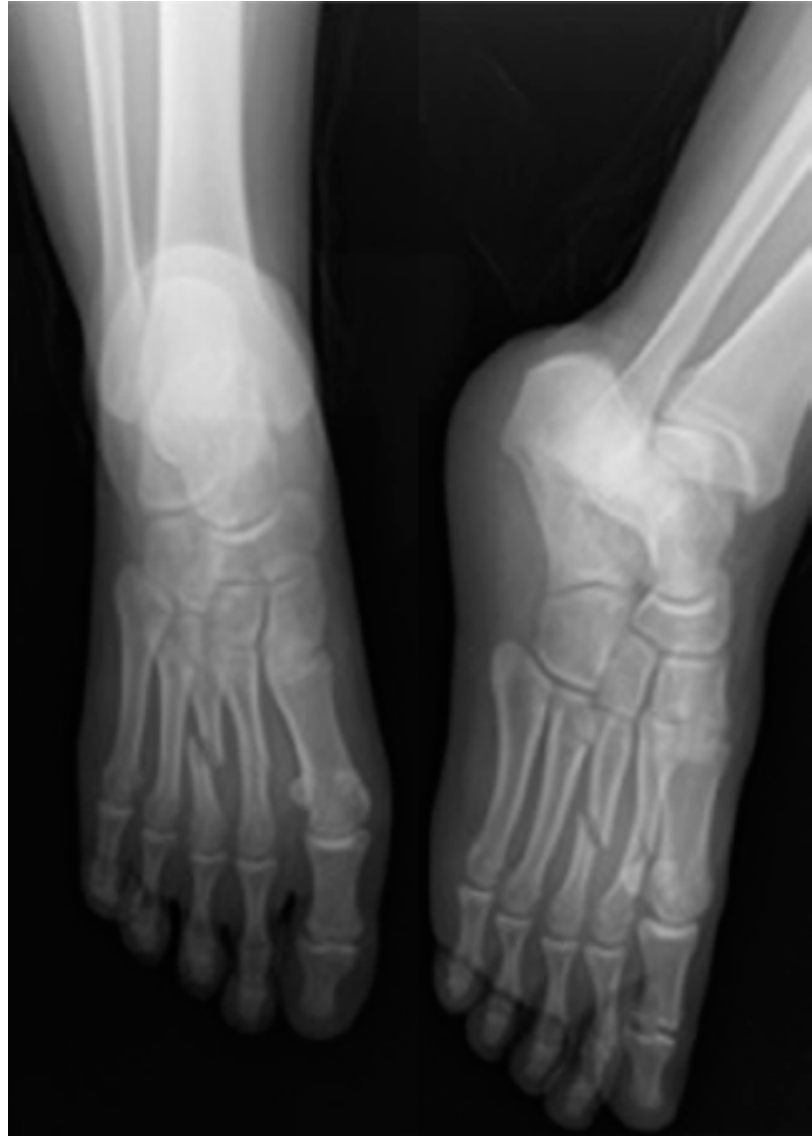

Şekil 7. Sağ ayak 2.-3. metatars diyafiz, 4. metatars proksimal uç kırıkları olan 13 yaşında kadın hastanın, ilk başvurusunda çekilen radyografileri.

\section{FALANKS KIRIKLARI}

Falanks kırıkları pediatrik popülasyonda sık görülür. Bu kırıkların çoğu semptomatik olarak tedavi edilir. Falanks kırıkları pediatrik ayak kırıklarının yaklaşık \%20'sini oluşturur. ${ }^{[15]}$ Falanks kırıklarının çoğunluğu Salter-Harris Tip I veya II'dir. ${ }^{[6]}$ Fizik muayenede tırnak yatağı yaralanması olup olmadığı değerlendirilmelidir. Açık kırıklar; irrigasyon, debridman ve intravenöz antibiyotik tedavisi gerektirir. Germinal matrisi içeren tırnak yatağı yaralanmaları onarılmalıdır. ${ }^{[5]}$

Kapalı kırıklar nadiren redüksiyon gerektirir. Falanks kırıkları, iyi bir hizalama ile genellikle 3-4 hafta içinde iyileşir. ${ }^{[1]}$ Kırık iyileşmesi gerçekleşene kadar, hasta konforu için sert tabanlı bir ayakkabı kullanılabilir. ${ }^{[5,6]}$ Ayak 1. parmak proksimal falanksının, belirgin derecede açılanmış, eklem yüzeyinin \%25'inden fazlasının etkilendiği intra-artiküler veya $2 \mathrm{~mm}$ 'den fazla deplasmanı olan kırıklarında, açık veya kapaIı redüksiyon ve pinleme düşünülmelidir (Şekil 9). ${ }^{[6]}$ Büyüme arresti veya sertlik, falanks kırıklarının nadir sekellerindendir. ${ }^{[1]}$

\section{GIZLI AYAK KIRIKLARI}

Yeni yürümeye başlayan çocuklar, bazen travma öyküsü olmaksızın, akut ayak ağrısı şikâyeti ile başvurabilirler. Ayakta hassasiyet olmakla birlikte, sınırlarının

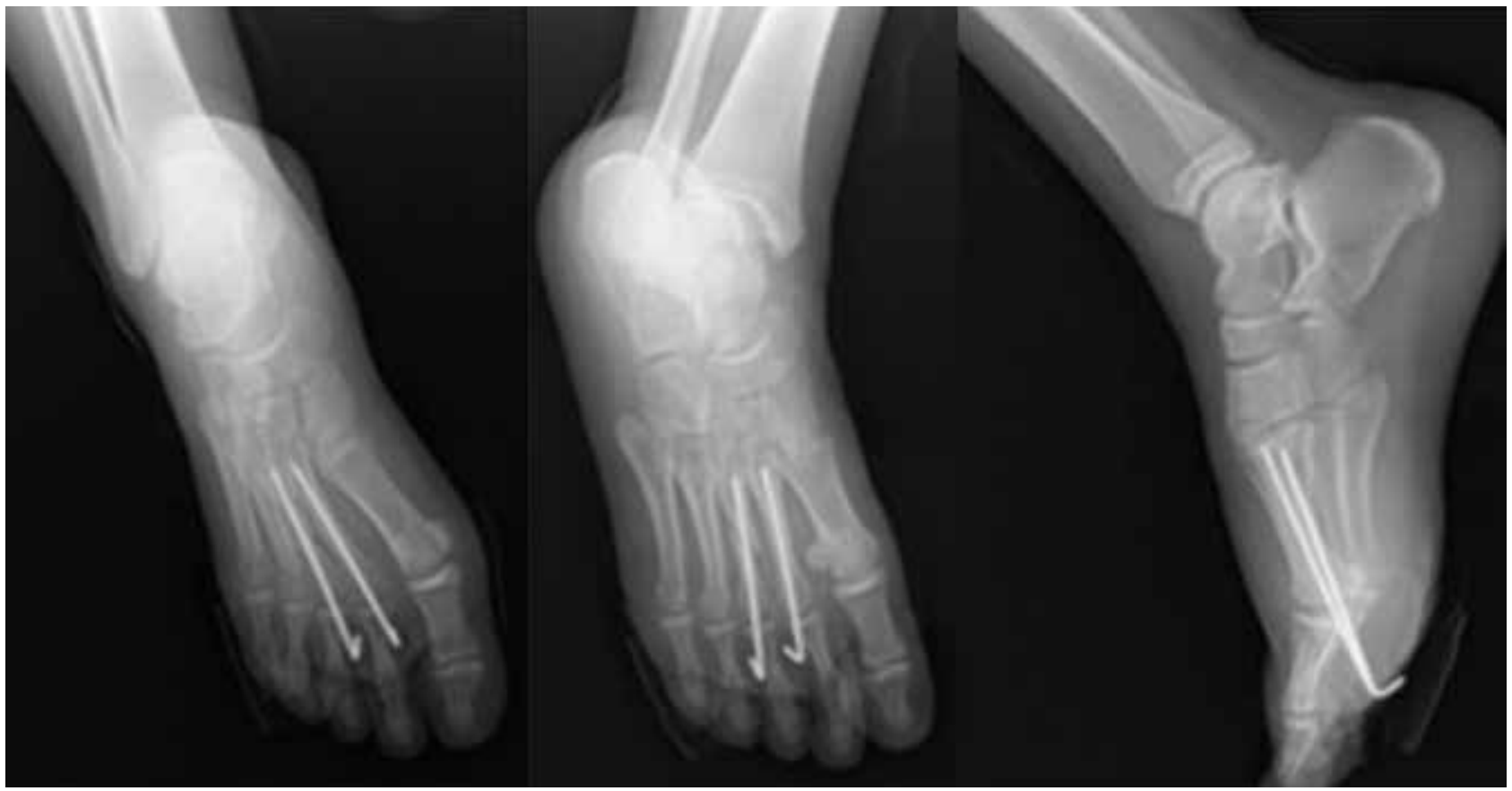

Şekil 8. Şekil 7'de operasyon öncesi radyografileri gösterilen hastanın, operasyon sonrası erken dönem radyografileri. 


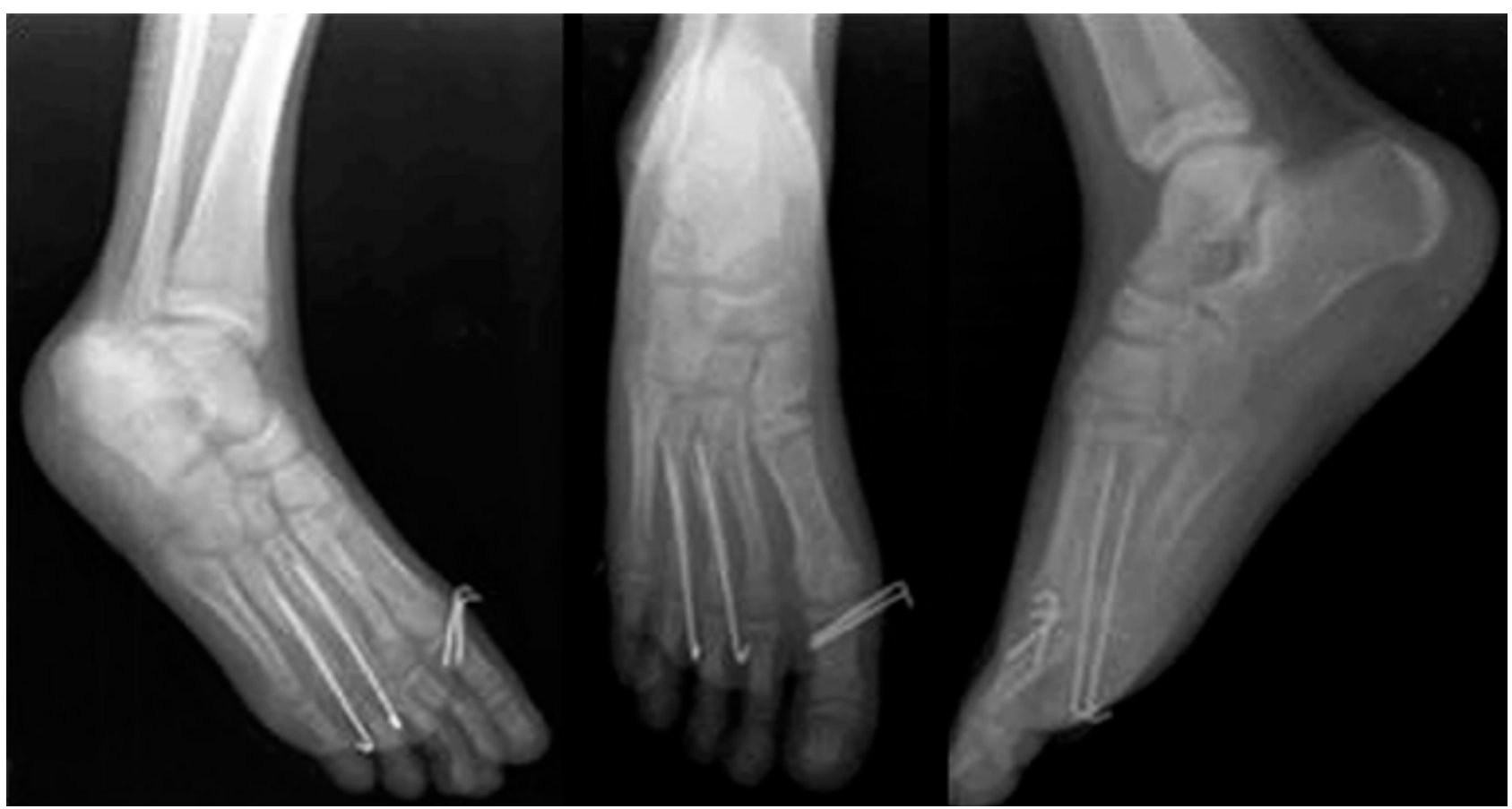

Şekil 9. Sağ ayak 1. parmak proksimal falanks ve 3.-4. metatars diyafiz kırıkları nedeniyle kapalı redüksiyon ve internal tespit yapılan yedi yaşında erkek hastanın, operasyon sonrası erken dönem radyografileri.

kesin olarak belirlenmesi zordur. Gizli ayak kırığı olan bir çocuk tipik olarak, emeklerken zorlanmamakla birlikte yürürken topallar. ${ }^{[2-4]}$ Düz radyografilerde nadiren kırık saptanır. Kemik taramasında, genellikle ayakta artmış radyonüklid alımı vardır. ${ }^{[2,5]}$

Gizli ayak kırı̆̆ı şüphesi varsa, 2-3 hafta kısa yürüme ateli tatbik edilebilir. Atel çıkarıldıktan sonra tekrarlanan radyografilerde kallus oluşumunun görülmesi, gizli ayak kırığı tanısını doğrular. Semptomlar devam ediyorsa ve kallus görülememişse, kemik taraması yapilmalıdır. ${ }^{[2]}$

\section{KAYNAKLAR}

1. Halai M, Jamal B, Rea P, Qureshi M, Pillai A. Acute fractures of the pediatric foot and ankle. World J Pediatr 2015;11(1):1420. Crossref

2. Dayton P, Feilmeier M, Coleman N. Principles of management of growth plate fractures in the foot and ankle. Clin Podiatr Med Surg 2013;30(4):583-98. Crossref

3. Polyzois VD, Vasiliadis E, Zgonis T, Ayazi A, Gkiokas A, Beris $\mathrm{AE}$. Pediatric fractures of the foot and ankle. Clin Podiatr Med Surg 2006;23(2):241-55. Crossref

4. Mayr J, Peicha G, Grechenig W, Hammerl R, Weiglein A, Sorantin E. Fractures and dislocations of the foot in children. Clin Podiatr Med Surg 2006;23(1):167-89. Crossref

5. Kay RM, Tang CW. Pediatric foot fractures: evaluation and treatment. J Am Acad Orthop Surg 2001;9(5):308-19. Crossref
6. Rammelt S, Godoy-Santos AL, Schneiders W, Fitze G, Zwipp $\mathrm{H}$. Foot and ankle fractures during childhood: review of the literature and scientific evidence for appropriate treatment. Rev Bras Ortop 2016;51(6):630-39. Crossref

7. Englanoff G, Anglin D, Hutson HR. Lisfranc fracturedislocation: a frequently missed diagnosis in the emergency department. Ann Emerg Med 1995;26(2):229-33. Crossref

8. Buckley SL, Gotschall C, Robertson W Jr, Sturm P, Tosi L, Thomas M, Eichelberger M. The relationships of skeletal injuries with trauma score, injury severity score, length of hospital stay, hospital charges, and mortality in children admitted to a regional pediatric trauma center. J Pediatr Orthop 1994;14(4):449-53. Crossref

9. Silas SI, Herzenberg JE, Myerson MS, Sponseller PD. Compartment syndrome of the foot in children. J Bone Joint Surg Am 1995;77(3):356-61. Crossref

10. Manoli A, Weber TG. Fasciotomy of the foot: an anatomical study with special reference to release of the calcaneal compartment. Foot Ankle 1990;10(5):267-75. Crossref

11. McCauley RG, Schwartz AM, Leonidas JC, Darling DB, Bankoff MS, Swan CS. Comparison views in extremity injury in children: an efficacy study. Radiology 1979;131(1):95-7. Crossref

12. Mizuta T, Benson WM, Foster BK, Paterson DC, Morris LL. Statistical analysis of the incidence of physeal injuries. J Pediatr Orthop 1987;7(5):518-23. Crossref

13. Rammelt $S$, Grass R, Schikore $H$, Zwipp $H$. Injuries of the Chopart joint. Unfallchirurg 2002;105(4):371-83. Crossref

14. Hawkins LG. Fractures of the neck of the talus. J Bone Joint Surg Am 1970;52(5):991-1002. Crossref 
15. Jensen I, Wester JU, Rasmussen F, Lindequist S, Schantz K. Prognosis of fracture of the talus in children 21(7-34)-year follow-up of 14 cases. Acta Orthop Scand 1994;65(4):398400. Crossref

16. Letts RM, Gibeault D. Fractures of the neck of the talus in children. Foot Ankle 1980;1(2):74-7. Crossref

17. Lauge-Hansen N. Fractures of the ankle. II. Combined experimental-surgical and experimental-roentgenologic investigations. Arch Surg 1950;60(5):957-85. Crossref

18. Inokuchi S, Usami N, Hiraishi E, Hashimoto T. Calcaneal fractures in children. J Pediatr Orthop 1998;18(4):469-74. Crossref

19. Greenspoon J, Rosman M. Medial osteochondritis of the talus in children: review and new surgical management. J Pediatr Orthop 1987;7(6):705-8. Crossref

20. Brunet JA. Calcaneal fractures in children. Long-term results of treatment. J Bone Joint Surg Br 2000;82-B(2):211-6. Crossref
21. Schantz K, Rasmussen F. Good prognosis after calcaneal fracture in childhood. Acta Orthop Scand 1988;59(5):5603. Crossref

22. Thomas HM. Calcaneal fracture in childhood. Br J Surg 1969;56(9):664-6. Crossref

23. Schneidmueller D, Dietz HG, Kraus R, Marzi I. Calcaneal fractures in childhood: a retrospective survey and literature review. Unfallchirurg 2007;110(11):939-45. Crossref

24. Yu GR, Zhao HM, Yang YF, Zhou JQ, Li HF. Open reduction and internal fixation of intra-articular calcaneal fractures in children. Orthopedics 2012;35(6):874-9. Crossref

25. Johnson GF. Pediatric Lisfranc injury: "bunk bed" fracture. AJR Am J Roentgenol 1981;137(5):1041-4. Crossref

26. Wiley JJ. Tarso-metatarsal joint injuries in children. J Pediatr Orthop 1981;1(3):255-60. Crossref 